\title{
Effects of Chronic Organic Arsenic Exposure on Rats Kidney - Light Microscopy and Electron Microscopy Study
}

Wan Muhamad Salahudin Wan Salleh¹, Norlelawati A. Talib², Nor Zamzila Abdullah², Sanda Aung ${ }^{3}$, Zunariah Buyong ${ }^{1}$

${ }^{1}$ Department of Basic Medical Sciences, Kulliyyah of Medicine, International Islamic University Malaysia

2Department of Pathology and Laboratory Medicine, Kulliyyah of Medicine, International Islamic University Malaysia

${ }^{3}$ Department of Basic Medical Sciences, Kulliyyah of Pharmacy, International Islamic University Malaysia.

Presenter: Wan Muhamad Salahudin Wan Salleh

Introduction: Monosodium methylarsonate (MSMA) is an organic arsenical pesticide widely used in agriculture. Humans are exposed to arsenic through drinking water and anthropogenic activities. Exposure to inorganic arsenic has been linked with multiple health problems. However, studies focusing on chronic organic arsenic exposure and its adverse effects on kidney were limited. The purpose of current study was to determine the effects of chronic organic arsenic exposure in rats kidney by light and electron microscopy. Materials and Method: Thirty-six male SpragueDawley rats were divided into six groups $(n=6)$; three control and three treatment group respectively. All the control group was given distilled water via oral gavage. The treatment group was given oral gavage of MSMA at $42.10 \mathrm{mg} / \mathrm{kg}$ body weight (BW) which is equivalent 1/30 LD50 of MSMA. The control and treatment groups were sacrificed at two month, four month and six months interval. Both kidneys harvested for light microscopy and electron microscopy study. Results: Showed progressive changes. The changes initially focal and became diffused involving glomerular; such as glomerular hypercellularity, glomerular shrinkage and dilated Bowman's space. Meanwhile, in proximal tubules, showed diminished brush borders, detachment of nucleus and basement membrane thickening. Electron microscopy showed flattened cell bodies of podocytes, effacement and fusion of podocytes foot processes, thickening of glomerular basement membrane, and discontinuity of brush border. The control and two-months treated group appeared to be normal. Conclusion: Chronic organic arsenic (MSMA) exposure induced chronic kidney injury. 